\title{
Effective Conditioning Program for Junior Tennis Players
}

\author{
Garg Isha ${ }^{1}$, Khurana Sonal ${ }^{*}$, Kadyan Gaurav ${ }^{3}$ and Tyagi Pragalbha ${ }^{4}$ \\ ${ }^{1}$ Physiotherapist, Aktiv Health, India \\ ${ }^{2}$ Senior Physiotherapist and Assistive Technology Analyst, Indian Spinal Injuries Centre, India \\ ${ }^{3}$ Assistant Professor, Indian Spinal Injuries Centre, India \\ ${ }^{4}$ Physiotherapist, Dr. Baba Saheb Ambedkar Hospital, India
}

Submission: May 10, 2018; Published: May 21, 2018

*Corresponding author: Khurana Sonal, Senior Physiotherapist and Assistive Technology Analyst, Indian Spinal Injuries Centre, India, Tel: 9891789887; Email: sonal8khurana@gmail.com

Abstract

Speed, agility and quickness are some of the most significant \& visible components of athletic success. An improvement in the ability to react quickly and to redirect that force if needed is the ultimate goal of a program to improve speed, agility and quickness.

Purpose and Significance: The purpose of the study was to examine the effect of 4week SAQ protocol on agility and aerobic capacity in junior tennis players.

Methodology: Research was carried out on a sample of fifty healthy tennis players from the sports complexes (aged: 14.2 \pm 0.9 ; height: $160.6 \pm 6.2 \mathrm{~cm}$; weight: $57.3 \pm 5 \mathrm{kgs}$ ). The players were randomly divided into training group and control group. The training group received four weeks of speed, agility and quickness protocol three days per week and the control group performed their regular training under the direct supervision of the therapist. The pre and post testing for the agility (t-test) and aerobic capacity (cooper test) was done at 0 week and after 4 weeks.

Result: The pre-test readings of t-test $\{$ training group $(11.246 \pm 1.09)$ and control group $(10.933 \pm 1.093)\}$ and post-test readings were \{training group (10.1712 \pm 0.93$)$ and control group (10.6848 \pm 0.85$)\}$ which concluded a significant improvement (0.05). Similarly, with aerobic capacity, training group $(24.3152 \pm 6.7$ vs $30.1176 \pm 8.1)$ and control group $(22.9 \pm 6.54$ vs $23.7 \pm 6.6)$.

Conclusion: The study concluded that SAQ protocol can improve both the agility and aerobic capacity in tennis players.

Keywords: SAQ protocol; Agility; Aerobic capacity

\section{Introduction}

Tennis is a sport that requires a variety of physical attributes: speed, agility, power, endurance, flexibility and strength as well as tennis-specific skills. Speed, agility and quickness are some of the most significant and visible components of athletic success. An improvement in the ability to react quickly and to redirect that force if needed is the ultimate goal of a program to improve speed, agility and quickness [1]. SAQ training involves learned motor skills. Although the magnitude of proficiency will vary with each individual learning the efficient and effective execution of these skills can improve overall athletic activity [2]. The training is intended to increase the ability to exert maximal force during high-speed movements. Some benefits include increased muscular power in all multiplanar movements, brain signal efficiency, kinesthetic spatial awareness, motor skills and reaction time. Many athletes and coaches do not realize that SAQ training can cover the complete spectrum of training intensity from low to high [3]. Although tennis is one of the most popular sports worldwide; however few studies have been conducted on physical demands during play. A better understanding of the demands, estimation of energy expenditure is required that enables a comparison to be made between tennis \& other forms of physical activity from a health perspective [4].

It is recognized that aerobic capacity (maximal oxygen uptake, $\mathrm{VO}_{2} \max$ ) is an important component of tennis 
performance \& enables the player not only to repeatedly generate explosive actions, but also ensures fast recovery between allies, especially during long matches [5]. Evidence suggests that motor skills such as power, strength, agility, speed and explosiveness as well as mental strength \& a highly developed neuromuscular coordinating ability are strongly correlated with tournament performance. Therefore, improvement of these attributes is indispensable to reach the international performance level. The processes of adaptation in top ranked players induced by years of training and match play include changes in heart size, maximum oxygen uptake $\mathrm{VO}_{2}$ max), onset of lactate production, heart rate, blood pressure, and hormonal regulation [6]. Since the effectiveness of SAQ protocol on performance of junior tennis players has not been proved previously, so the study is focused on determining the effectiveness of the protocol.

\section{Materials and Methods}

50 subjects were taken from sports complex. Out of which 5 subjects could not complete the training. The players taken were under-16 national level who have been playing for last 2 years and were able to complete $12 \mathrm{~min}$ walk/run test. Before the initiation of training, experimental and control groups underwent a pre-testing procedure for aerobic capacity using 12 minute cooper walk/run test and agility using T-test. Before training, subjects completed their regular warm up session of 10 minutes. Experimental group underwent speed agility and quickness training for 3 days $\mathrm{x} 4$ weeks. Control group continued with their regular training program. Post-testing was completed after 4 weeks of training program. After completion of the training, data was collected and analysed (Tables 1-4).

Table 1: Agility.

\begin{tabular}{|c|c|}
\hline Line drills & Description \\
\hline Lateral jumps & $\begin{array}{l}\text { Place a jump rope straight on the floor and jump back and forth laterally over the rope rapidly, just high and far } \\
\text { enough to clear the rope. Do } 3 \text { sets of 10-15 seconds with a 1-minute rest break between sets. }\end{array}$ \\
\hline Forward/backward jumps & $\begin{array}{l}\text { Using the same rope, jump forward and backward rapidly over the rope just high and far enough to clear the rope. } \\
\text { Do } 3 \text { sets of 10-15 seconds with a 1-minute rest break between sets. }\end{array}$ \\
\hline Cycling & $\begin{array}{l}\text { Using the same rope, straddle e the rope with your feet perpendicular to it. Change your foot position in rapid } \\
\text { succession, moving just high and far enough to clear the rope. Do } 3 \text { sets of } 10-15 \text { seconds with a 1-minute rest } \\
\text { break between sets. }\end{array}$ \\
\hline Criss-cross & $\begin{array}{l}\text { Using the same rope, straddle the rope and rapidly change foot position by crossing the right foot in front of the } \\
\text { left bringing it to the other side of the rope while at the same time crossing the left foot in back of the right foot } \\
\text { bringing it to the other side of the rope. Do } 3 \text { sets of 10-15 seconds with 1-minute rest breaks. }\end{array}$ \\
\hline Angle board & $\begin{array}{l}\text { Stand in the center of the board and step across with the right foot onto the angle piece. Return to the starting } \\
\text { position and do the same movement to the left. Do } 3 \text { sets of 10-15 seconds with a 1-minute rest beak. }\end{array}$ \\
\hline Box drill: step on & $\begin{array}{l}\text { Stand in the center of the box and place one foot on the box with the other on the ground. With quick succession, } \\
\text { alternate the feet while jumping in the air. This exercise is completed without stopping. Do } 3 \text { sets of 10-15 } \\
\text { seconds with a 1-minute rest break. }\end{array}$ \\
\hline
\end{tabular}

Table 2: Speed.

\begin{tabular}{|c|c|}
\hline Drills & Description \\
\hline Partner assisted let go & $\begin{array}{r}\text { Mimic a running posture by leaning forward and having a partner support the front of the runner's shoulders } \\
\text { to prevent them from falling forward. On the count, the partner lets go and steps aside while the runner } \\
\text { breaks into a sprint. Do 3 sets of 6-8 reps with 2-3-minute rest breaks. }\end{array}$ \\
\hline Partner resisted Runs & $\begin{array}{r}\text { Mimic a running posture as in the above exercise and have the runner run while the partner resists. Do 6-8 } \\
\text { repetitions lasting about 10 yards with 2-3 minute rest breaks. }\end{array}$ \\
\hline $\begin{array}{c}\text { Partner resisted run with let-go } \\
\text { Partner resisted run with let-go } \\
\text { plus tag }\end{array}$ & $\begin{array}{r}\text { This exercise is the same as above, but after 5 yards of resisted running, the partner lets go and steps aside } \\
\text { awayner breaks into a short sprint. }\end{array}$ \\
\hline
\end{tabular}

Table 3: Lower/Upper Body Quickness

\begin{tabular}{|c|c|}
\hline Cone drills & Description \\
\hline Lateral shuffle & $\begin{array}{c}\text { Place } 2 \text { cones about 15-20 feet apart and stand in the middle of the cones. Shuffle laterally to the left cone and } \\
\text { touch the top of the cone and then shuffle to the right and touch the other cone. Repeat for a total of } 10 \text { cone } \\
\text { touches. }\end{array}$ \\
\hline Forward/backward running & $\begin{array}{r}\text { Using the same cone setup as in the lateral shuffle, stand near the base of } 1 \text { cone and run forward to the other } \\
\text { cone. Circle this cone and run backward toward the first cone. Repeat this pattern for } 3 \text { sets of 6-8 reps. }\end{array}$ \\
\hline Zig-zag & $\begin{array}{r}\text { Position } 6 \text { cones about 6-8 feet apart in the shape of continuous letter "W, and run through the cones to the } \\
\text { outside of each cone, working on changing directions quickly. Repeat for } 3 \text { sets of } 6 \text { reps. }\end{array}$ \\
\hline
\end{tabular}




\begin{tabular}{|c|c|}
\hline Medicine ball drills Chest pass & $\begin{array}{c}\text { Standing in an athletic ready posture and hold the ball close to your chest, just below the chin. In an explosive } \\
\text { motion, throw the ball from the chest to a partner. As the partner throws the ball back, catch the ball in front } \\
\text { of the body and throw the ball back again. Catch and throw the ball as quickly as possible. Do } 3 \text { sets of 8-12 } \\
\text { reps with 1-2 minute rest breaks. }\end{array}$ \\
\hline Overhead throw & $\begin{array}{c}\text { Standing in an athletic ready posture, hold the ball with hands on opposite sides of the ball and bring it } \\
\text { overhead to just behind the neck and throw the ball to a partner in an all out explosive motion. Do } 3 \text { sets of } \\
8-12 \text { reps. }\end{array}$ \\
\hline Lateral throw & $\begin{array}{c}\text { Standing in an athletic ready posture, hold the ball below the waist with arms straight. In a pendulum- like } \\
\text { motion, reach to the left and explode back to the right, throwing the ball to a partner. Do 3 sets of 8-12 reps on } \\
\text { each side of the body. }\end{array}$ \\
\hline
\end{tabular}

Table 4: Program Design.

\begin{tabular}{|c|r|}
\hline Monday & $\begin{array}{r}\text { Agility: angle board, } 3 \text { sets; criss-cross line drill, } 3 \text { sets. } \\
\text { Quickness: zig-zag cone drill, } 3 \text { sets; lateral shuffle, } 3 \text { sets. }\end{array}$ \\
\hline Wednesday & $\begin{array}{r}\text { Agility: line drills and forward/backward jumps, } 3 \text { sets; cycling, } 3 \text { sets. } \\
\text { Speed: partner-assisted let-go, } 3 \text { sets; partner-resisted run with let-go, } 3 \text { sets. } \\
\text { Quickness: medicine ball drills, overhead throw, } 3 \text { sets of } 8 \text { reps; } \\
\text { chest pass, } 3 \text { sets } 8 \text { reps. }\end{array}$ \\
\hline Friday & Quickness: cone drills, lateral shuffle, 3 sets; forward/backward running, 3 sets; medicine ball drills, lateral throw, 3 sets \\
& of 8 reps.
\end{tabular}

\section{Data Analysis}

The data was managed on excel spread sheet and was analysed using SPSS (Statistical Package for the Social Sciences) software, version 17.0. For all statistical tests, the level of significance was set at $p$ value $\leq 0.05$. All values were expressed as mean and standard deviation (Figures $1 \& 2$ ). A paired t-test was applied to analyze the difference of t-test and aerobic capacity between pre- and post- intervention of junior tennis players in both experimental and control group. An independent t-test was applied to analyze the difference of t-test and aerobic capacity among the experimental and control group (Tables 5-7).

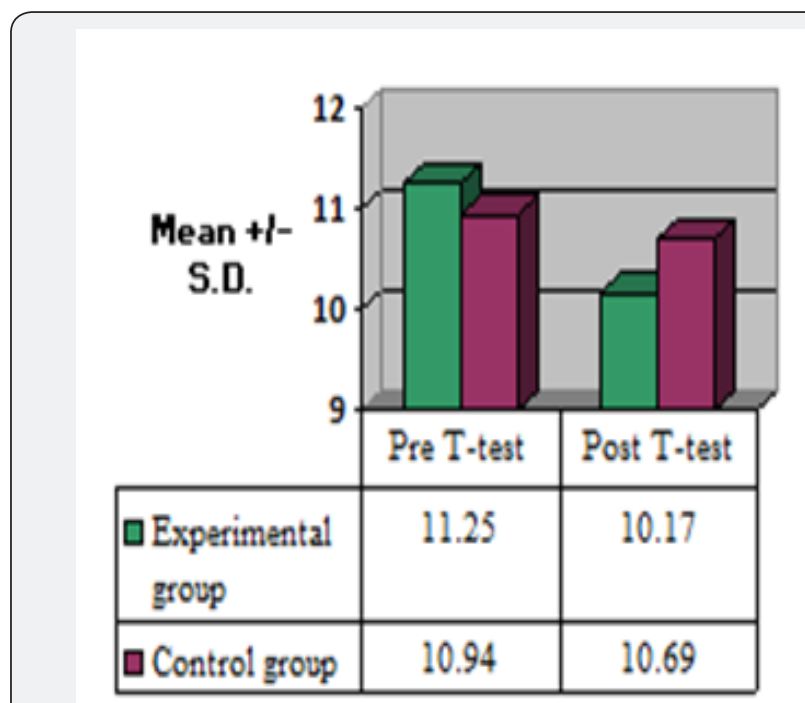

Figure 1: T-test for agility for 4 weeks of SAQ training program.

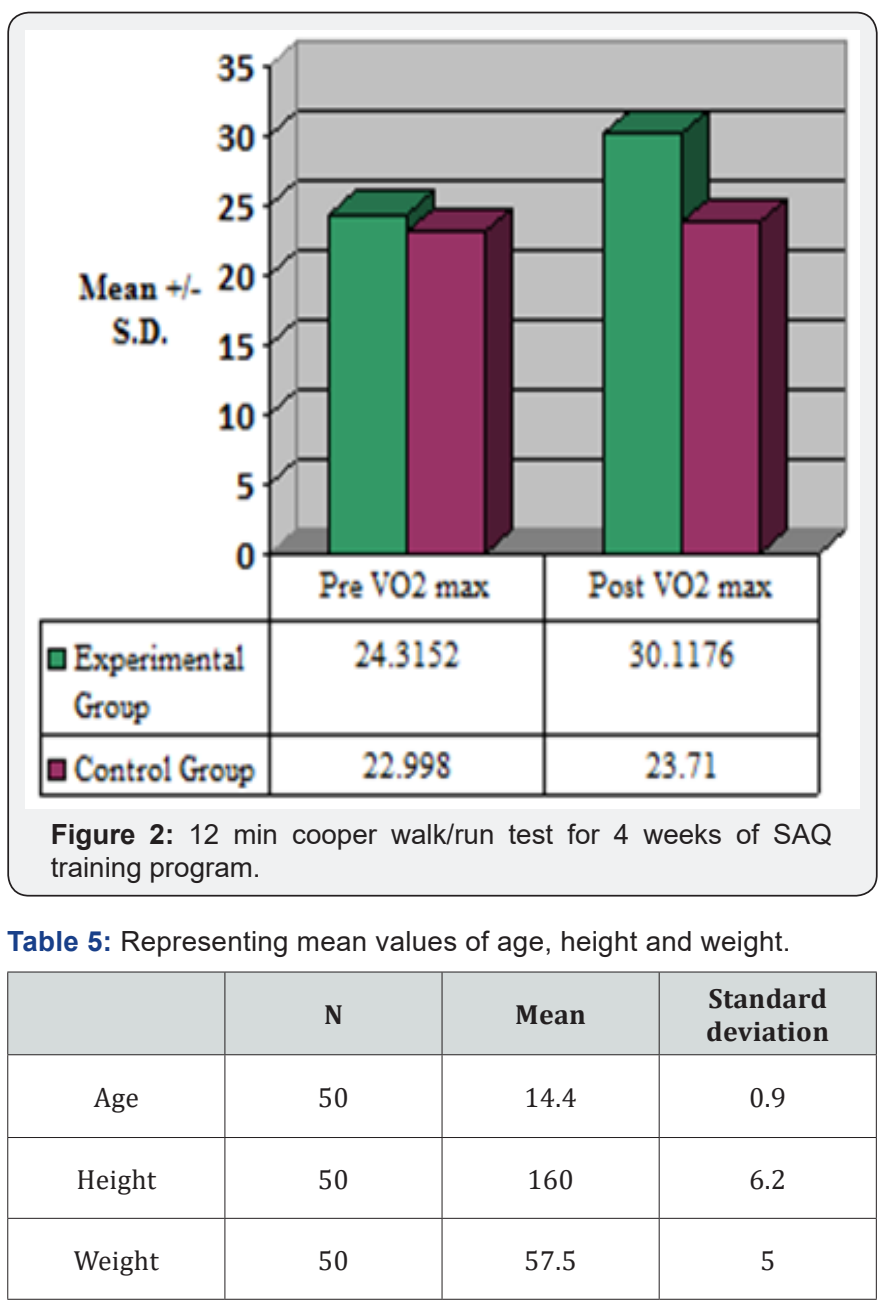


Table 6: Representing mean value, standard deviation, t-value and $p$ value for inter group for T-test.

\begin{tabular}{|c|c|c|c|c|c|c|}
\hline & Group & $\mathbf{N}$ & Mean & $\begin{array}{c}\text { Standard } \\
\text { deviation }\end{array}$ & t-value & p-value \\
\hline \multirow{2}{*}{$\begin{array}{c}\text { Pre } \\
\text { T-test }\end{array}$} & EXP & 25 & 11.2460 & 1.0944 & \multirow{2}{*}{1.038} & 0.304 \\
\cline { 2 - 6 } & CNTR & 25 & 10.9336 & 1.0319 & & \\
\hline \multirow{2}{*}{$\begin{array}{c}\text { Post } \\
\text { T-test }\end{array}$} & EXP & 25 & 10.1712 & 0.9387 & \multirow{2}{*}{2.017} & 0.049 \\
\cline { 2 - 6 } & CNTR & 25 & 10.6848 & 0.8598 & & \\
\hline
\end{tabular}

Table 7: Presenting mean value, standard deviation, $t$-value and level of significance for aerobic capacity.

\begin{tabular}{|c|c|c|c|c|c|c|}
\hline & Group & $\mathbf{N}$ & Mean & $\begin{array}{c}\text { Standard } \\
\text { deviation }\end{array}$ & t-value & p-value \\
\hline \multirow{2}{*}{$\begin{array}{c}\mathrm{Pre} \mathrm{VO}_{2} \\
\mathrm{max}\end{array}$} & 1 & 25 & 24.3152 & 6.7675 & \multirow{2}{*}{0.700} & 0.488 \\
\cline { 2 - 6 } & 2 & 25 & 22.9980 & 6.5446 & & \\
\cline { 1 - 5 } $\begin{array}{c}\text { Post } \\
\mathrm{VO}_{2} \\
\mathrm{max}^{2}\end{array}$ & 1 & 25 & 30.1176 & 8.1024 & \multirow{2}{*}{3.05} & 0.004 \\
\cline { 2 - 6 } & 2 & 25 & 23.7068 & 6.6669 & & \\
\hline
\end{tabular}

\section{Discussion}

Several studies have been performed in the past few years emphasizing on utility of speed agility and quickness training. This study shows that four weeks of speed agility and quickness training program was found to be effective in improving aerobic capacity using cooper test and agility using T-test in junior tennis players. This study shows a significant improvement in agility in experimental group $(\mathrm{p}<0.01)$ as compared to the control group $(\mathrm{p}<0.05)$. The reason for improvement in agility in experimental group may be due to effect of training on neuromuscular control and motor skill function. The participants initially executed the exercises at low speeds to ensure the development of appropriate technique. It seems that specific focus of training augmented neuromuscular control over the 4 weeks period. Improvement in strengths, therefore, improves game related activities such as changing of directions. Motor learning and physical conditioning as according to principle of specificity is the key to enhance neuromuscular control [4].

With training, improvement can be either due to better motor recruitment or neural adaptation. Neural adaptation occurs when athletes respond or react as a result of improved coordination between the CNS signal and proprioceptive feedback. Training challenges the player's neuromuscular efficiency to maintain COG over changing base of support with constantly changing directions at varying speeds. Thus training to improve movement not only increases functional capabilities, but also helps in advanced integration of the neural and muscular system while moving at different speed and in different planes of motion [2].

Speed agility and quickness training also develops an athlete's ability to be more skillful at faster speeds and with greater precision. This enables to become better at reacting to stimuli, starts more quickly and efficiently, move effectively in multiple directions and change of directions or stop quickly to make a play in a fast, smooth, efficient and repeatable manner. This specific focus of training augments neuromuscular control over four week training period. The training re-enforces motor programming through neuromuscular conditioning and neural adaptations of muscle spindles, Golgi tendon organ and joint proprioception. Neural adaptation occurs because of improved coordination between CNS signal and proprioceptive feedback [4].

SAQ training also decreases fatigue time in sprints, agility drills and increased vertical and horizontal jump distances. Thus, training improves proprioceptive ability of the joint which influences neuromuscular firing pattern leading to reduced risk and thereby augmenting performance [2]. Also according to the SAID, the exercises that mimic motions in the sport have the greatest impact on performance. In the protocol, the exercises that include change of directions such as in zig-zag running may help improve the agility scores of the players [7]. There is also an increment of agility score in control group. The reason for improvement in control group may be due to their regular supervised tennis training sessions. On comparing the result for aerobic capacity in healthy junior tennis players it was found that aerobic capacity increases in experimental group. Although a small increase in aerobic capacity occurred in the control group but that was not statistically significant. The aerobic capacity in players increases as they covered a larger distance area in a limited time period. The capacity of covering the greater distance improves with less fatigue in a player after the training. Thus, improving player's ability to perform several sprints within a short period of time. The improvement in running of players is expected because of running training carried out during the training program. Thus covering large distance in less duration and thus improving the aerobic capacity of the players [8].

Though it cannot be judged objectively through this research but the results from the present study state a significant improvement in aerobic capacity in the age group (12-16 years). The SAQ program for 4 weeks laid stress on cardiovascular system of the subject that can be attributing for the improvement in aerobic capacity. Training might have resulted in increased skeletal muscle blood flow and vascular conductance, lactate transport capacity and $\mathrm{H}+$ ion release from active muscle, ionic regulation and sarcoplasmic reticulum function. Training also enhances mitochondrial enzymes that increase the rate of fat oxidation, sparing muscle glycogen and blood glucose and decreased lactate production during exercise that influence the $\mathrm{VO}_{2}$ max [9]. McArdle also states that an exercise duration that is for more than 10 minutes put stress on the aerobic system.

Due to exercise, there also occurs a physiological enlargement of the heart which is paralleled by an increase in stroke volume and maximum cardiac output. This, together with 
peripheral vascularisation and muscular substrate utilization, form the basis for increased oxygen uptake, $\mathrm{VO}_{2}$ max. The values for female tennis players reach up to $55 \mathrm{ml} / \mathrm{kg} / \mathrm{min}$ and for male tennis players reach up to $65 \mathrm{ml} / \mathrm{kg} / \mathrm{min}$. Studies have shown the importance of conditioning programs in improving aerobic performance. The increment in aerobic capacity may be due to a greater muscle involvement and increased time of contraction, thereby utilizing greater degrees of aerobic energy pathways [6]. Thus the SAQ training program helps in improving the performance of junior tennis players [10-17].

\section{Clinical Relevance of the Study}

From the present study we found that there is an improvement in agility score and aerobic capacity of junior tennis players [1726]. Thus the protocol can be used in enhancing the performance of athletes and it may also be used in future in reducing the injury rate of the athletes.

\section{Future Research}

a) Additional research is required to establish whether improvements seen by speed agility and quickness training on selected physical fitness tests would also result in improved tennis performance.

b) The protocol may further be used in detecting the decrease in rate of occurrence of injuries in athletes.

c) The protocol can be used in different athletic populations for enhancing their performance.

d) The effect of protocol can also be tested on core strength, dynamic balance [27-38].

\section{References}

1. George Mamassis (2010) Changes in agility and speed after a 10-week periodised training program in male tennis players. Sports Medicine \& Sciences in Tennis, p. 4-5.

2. Maman Paul, Sandeep Kumar Biswas, Gaurang Shukla, Jaspal Singh Sandhu (2011) Effect of agility training on tennis performance. J Med Sci Tennis 16(1): 21-25.

3. Akhil Mehrotra, Vikram Singh, Shyam Lal (2011) Effect of six weeks SAQ drills training programme on selected anthropometrical variables. Indian Journal of Movement Education and Exercises Sciences 1(1).

4. Remco Polman, Jonathan Bloomfield, Andrew Edwards (2009) Effects of SAQ Training and Small-Sided Games on Neuromuscular Functioning in Untrained Subjects. International journal of sports physiology and performance 4(4): 494-505.

5. Jonathan Bloomfield, Remco Polman, Peter O`Donoghue, Lars McNaughton (2007) Effective speed and agility conditioning methodology for random intermittent dynamic type sports. Journal of strength and conditioning research 21(4): 1093-1100.

6. Daniel Konig, Martin Huonker (2001) Cardiovascular, metabolic and hormonal parameters in professional tennis players. Med Sci Sports Exerc 33(4): 654-658.

7. Cameroon L Martz (1999) Increasing our fitness: How to get started. ACSM (H/F1), USA.

8. Helgerud Jan, Kjetill Hoydal, Jan Hoff, Ninal Hjorth (2007) Aerobic high-intensity intervals improve $\mathrm{VO}_{2}$ max more than moderate training. Medicine \& Science in Sports \& Exercise 39(4): 665-671.
9. William D McArdle, Frank I Katch, Victor L, Katch (2001) Exercise physiology: Energy nutrition and human performance. pp.1038.

10. Jovanovic Mario, Sporis Goran, Omrcen Darija, Fiorentini Fredi (2011) Effects of speed, agility, quickness training method on power performance in elite soccer players. Journal of Strength \& conditioning research 25(5): 1285-1292.

11. Jaime Fernandez Fernandez, David Sanz Rivas (2009) A comparison of the activity profile and physiological demands between advanced and recreational veteran tennis players. Journal of Strength and Conditioning 23(2): 604-610.

12. Olivier Girard, Gregoire P Millet (2009) Physical determinants on tennis performance in competitive teenage players. J Strength Cond Res 23(6): 1867-1872.

13. Lee E Brown, Joshua M Miller (2001) Speed, quickness and agility training for senior tennis players. Journal of Strength and Conditioning 23(5): 62-66.

14. Kevin Wink Improving Running Speed and Acceleration with a Resisted Sprint Ergo meter. Applied performance research p. 6.

15. Ales Filipcic, Sreco Zavrski (2002) Relation between two aerobic tests and competitive successfulness of junior tennis players. Kin SI 8(1): 5-9.

16. P Jones, TM Bampouras, K Marrin (2009) An investigation into the physical determinants of change of direction speed. J Sports Med Phy Fitness 49(1): 97-104.

17. Ales Filipcic, SrecoZavrski (2011) A comparison of some selected motor tests and competitive successfulness in tennis. Journal of Sports and Performance Researches 2: 12-21.

18. Pauole Kainoa, Madole, Kent, Garhammer, John, et al. (2000) Reliability and validity of the t-test as a measure of agility, leg power and leg speed in college- aged men and women. The Journal of Strength and Conditioning, USA.

19. Jason D Vescovi, Michael R, McGuigan (2008) Relationship between sprinting, agility and jump ability in female athletes. Journal of Sports Sciences 26(1): 97-107.

20. Nicolas JA Berger (2006) Influence of continuous and interval training on oxygen uptake on-kinetics. Med Sci Sports Exerc 38(3): 504-512.

21. S Grant, K Corbett, AM Amjad, J Wilson, T Aitchison (1995) A comparison of methods of predicting maximum oxygen uptake. $\mathrm{Br} J$ Sports Med 29(3): 147-152.

22. Jacob E Earp, William J Kraemer (2010) Medicinal ball training implications for rotational power sports. National Strength and Conditioning Association 32(4): 20-25.

23. CM Laurent, JM Green, PA Bishop, J Sjokvist, RE Schumacker (2010) Effect of gender on fatigue and recovery following maximal intensity repeated sprint performance. J Sports Med Phy Fitness 50: 243-253.

24. Ryota Uzu, Masahiro Shinya, Shingo Oda (2009) A split-step shortens the time to perform a choice reaction step and reach movement in a simulated tennis task. Journal of Sports Sciences 27(12): 1233-1240.

25. Barber Westin (2010) A six week neuromuscular training program for competitive junior tennis players. Journal of Strength and Conditioning Research 24(9): 2372-2382.

26. Avery D Faigenbaum, Patrick Mediate (2006) Effects of medicine ball training on fitness performance of high school physical education students. Fall 160-167.

27. Bart Drinkard, Jennifer McDuffie, Serena McCann, Jack A Yanovski (2001) Relationships between walk/run performance and cardiorespiratory fitness in adolescents who are overweight. Physical Therapy 81(12): 1889-1896. 
28. J Fernandez, A Mendez Villanueva, BM Pluim (2006) Intensity of tennis match play. Br J Sports Med 40(5): 387-391.

29. Fernandez Fernandez (2009) A comparison of the activity profile and physiological demands between advanced and recreational veteran tennis players. J Strength Cond Res 23(2): 1-7.

30. Carl D Paton (2004) Effects of high intensity training on performance and physiology of endurance athletes. Sports Science 8: 25-40.

31. Veronique L Billat, Bruno Flechet, Bernard Petit, Jean Pierre Koralsztein (1999) Interval training at $\mathrm{VO}_{2}$ max: effects on aerobic performance and overtraining markers. Med Sci Sports Exerc 31(1): 156-163.

32. Souhail Hermassi (2011) Relationship between agility T-test and physical fitness measures as indicators of performance in elite handball players 5: 125-131.

33. Remco Polman (2004) Effective conditioning of female soccer players. Journal of Sports Sciences 22: 191-203.
34. Van Gelder, Bartz SD (2011) The effect of acute stretching on agility performance. Journal of Strength and Conditioning 25(11): 3014 3021.

35. Maman Paul, Sandeep K Biswas, Gaurang Shukla, Jaspal S Sandhu (2011) Effect of agility training on tennis performance. J Med Sci Tennis 16(1): 21-25.

36. Mario Leone, Alain S, Comtois, Luc Leger (2006) Specificity of running speed and agility in competitive junior tennis players. Medicine \& Science in Tennis 11(1): 10-11.

37. Jan Helgerud, Lars Christian Engen, Jan Hoff (2001) Aerobic endurance training improves soccer performance. Med Sci Sports Exerc 33(11): 1925-1931.

38. David R Bassett, Edward T Howley (2000) Limiting factors for maximum oxygen uptake and determinants of endurance performance. Med Sci Sports Exerc 32(1): 70-84.

\section{Your next submission with Juniper Publishers will reach you the below assets}

- Quality Editorial service

- Swift Peer Review

- Reprints availability

- E-prints Service

- Manuscript Podcast for convenient understanding

- Global attainment for your research

- Manuscript accessibility in different formats

( Pdf, E-pub, Full Text, Audio)

- Unceasing customer service

Track the below URL for one-step submission https://juniperpublishers.com/online-submission.php 